\title{
Thrombosis and Haemostasis Wishes You a Happy New Year Ahead!
}

\author{
Gregory Y. H. Lip ${ }^{1}$ Christian Weber ${ }^{2}$ \\ ${ }^{1}$ Liverpool Centre for Cardiovascular Science, Institute of Ageing and \\ Chronic Disease, University of Liverpool, Liverpool, United Kingdom \\ 2 Institute for Prevention of Cardiovascular Disease, Ludwig- \\ Maximilians University of Munich, Munich, Germany
}

Thromb Haemost 2019;119:1-2

\section{WELCOME to 2019!}

We are pleased to embrace the New Year with our traditional January Editorial and Editors' Choice. ${ }^{1}$

First, we would like to express our deepest thanks to all of you, our faithful readers and authors who have kept Thrombosis and Haemostasis (T\&H) strong and healthy through the years.

In 2018, we received around 900 submissions from you again, a steady number which reflects the trust you place in our Journal. Portraying this, our impact factor has followed a stable trend since it reached 5 in 2011 similarly to our CiteScore which remains around 4 .

We continue to serve as a link journal for the European Society of Cardiology Working Groups on Thrombosis and on Atherosclerosis \& Vascular Biology, as well as being the official journal of the Society of Thrombosis and Haemostasis Research (GTH), the Spanish (SETH) Society on Thrombosis and Haemostasis and the Australian Vascular Biology Society (AVBS).

\section{Reviewers}

We are deeply grateful to our near 900 dedicated referees who do their best to providing reviews in a timely, highly competent and comprehensive manner.

A special appreciation goes to our top 10 reviewers for 2018:

- Dominick Angiolillo

- Erik Klok

- Ton Lisman

- Piera Capranzano

- Robert Storey

- Luca Liberale

- Marco Proietti

- Dirk Sibbing

- Hugo ten Cate

- Dietmar Trenk

received

December 3, 2018

accepted

December 3, 2018

Address for correspondence Gregory Y. H. Lip, MD, Liverpool Centre for Cardiovascular Science, Institute of Ageing and Chronic Disease, University of Liverpool, William Henry Duncan Building, 6 West Derby Street, Liverpool L7 8TX, United Kingdom (e-mail: gregory.lip@liverpool.ac.uk).

\section{Section Editors}

We bid farewell to Robert K. Andrews (Australia), Raffaele De Caterina (Italy), Victor Jiménez Yuste (Spain), Pieter W. Kamphuisen (Netherlands) and Irene M. Lang (Austria). We thank them for their dedication as well as their reliable insights and professional comments and look forward to future collaborations and interactions.

We also give a warm welcome to our new colleagues on the Editorial Board: James Douketis (Canada), Diana Gorog (U.K.), Ramón Lecumberri (Spain) and Cheng-Hock Toh(U.K.) who have joined as new section editors.

A special thank you goes to our last year's 7 most proactive section editors:

- Tatjana Potpara

- Job Harenberg

- Sam Schulman

- Walter Ageno

- Deirdre Lane

- Francesco Violi

- Jeffrey Weitz

\section{What's New?}

\section{New Publisher, New Look}

With this issue, we proudly introduce a new cover design reflecting our successful move to the Thieme Publisher group. We are happy that T\&H now visually matches the very distinct look from Thieme, a very strong brand which is known worldwide for high-quality medical publishing. The new layout features a prominent place for each month's cover image as well as Highlights focusing on the essential, to better engage the reader.

\section{From the Latest to the Oldest}

We are delighted to announce the full retro-digitalization of T\&H this year, available on our new online archive system on www.thieme-connect.com. Not only can you follow our

(c) 2019 Georg Thieme Verlag KG Stuttgart · New York
DOI https://doi.org/ $10.1055 / \mathrm{s}-0038-1676651$. ISSN 0340-6245. 


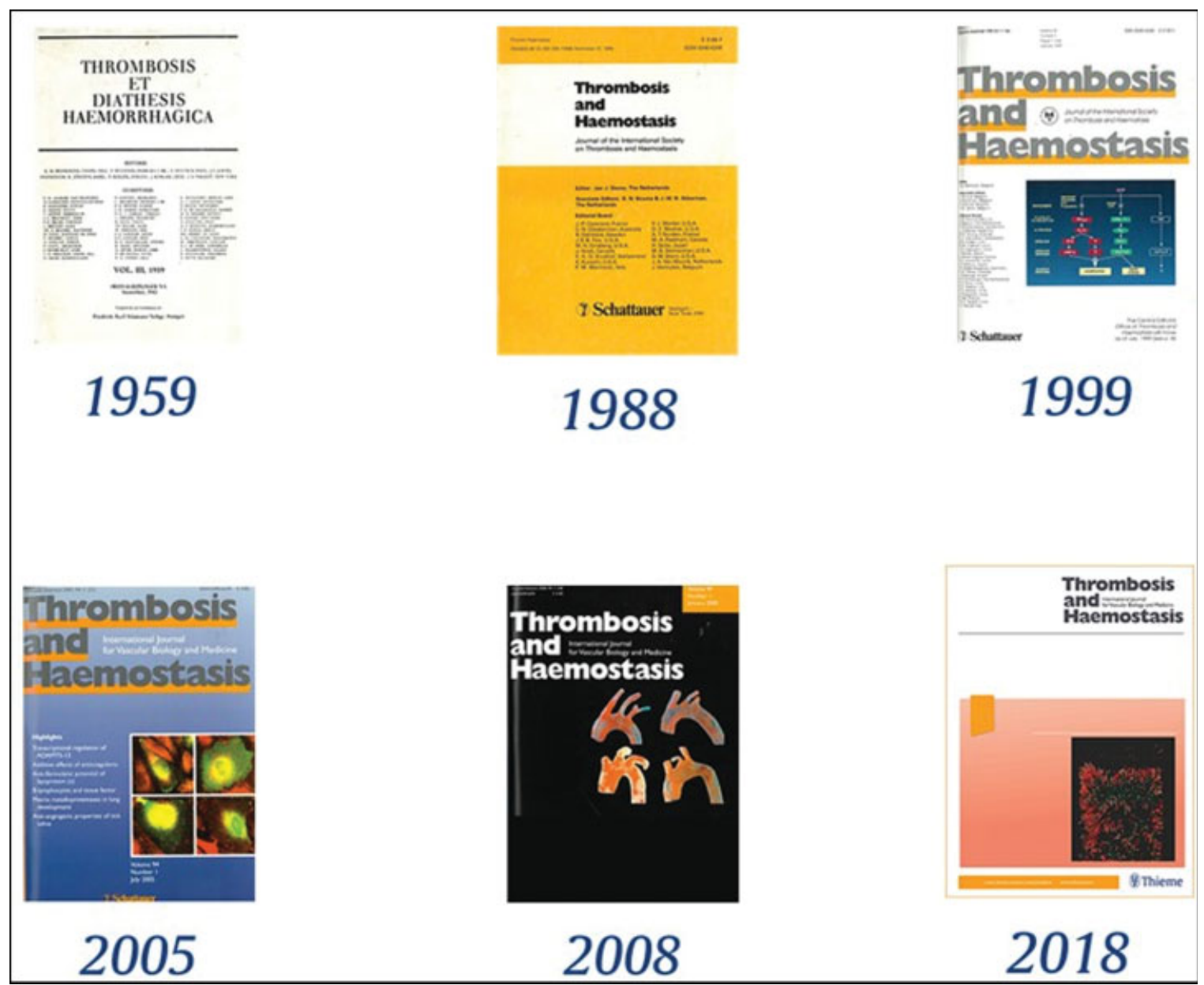

How the cover design has evolved over the years.

latest publications on the T\&H website, but you are now also able to browse through all issues dating back to 1957 , representing your past 61 years of hard work and findings!

\section{Like, Share and Tweet!}

Aside from the publisher's website, you are cordially invited to follow us on our social media pages, which we regularly update with news, links and short interviews from authors whose findings particularly stroke our interest. Please pay us a visit, and don't hesitate to like, share and re-tweet with your colleagues and friends!

https://twitter.com/TH_Journal

f https://www.facebook.com/thrombosisandhaemostasis

\section{TH Open}

We are pleased to announce that our new 'baby', the open access companion journal TH Open is growing well, with more than 70 manuscripts published since its launch in 2017 and PubMed visibility. Its unique 'Pay What You Want' policy allows authors to decide how much worth they place into the publication process and give a chance to those who are deterred by high publishing prices to submit Open Access.

As an additional remark pro domo, we have to say goodbye to Irina Moshkova, who handled the editorial office for almost 10 years and has now parted for new shores. We would like express our heartfelt gratitude to Irina for the excellent work and service to the journal over the years and at the same time welcome Dr. Anne Rigby, who joined the team this year and will supervise the editorial office and all its needs with all commitment.

Finally, along with the entire editorial staff including Dr. Elinor Switzer (Stuttgart), Dr. Anne Rigby (Munich) and Thieme Publisher(Stuttgart), we would again like to thank you, our authors and readers, for your support and trust as well as you, our section editors and reviewers, for your dedicated time and critical eye. It is with you that $\mathrm{T} \& \mathrm{H}$ can continue to be the reference to clinicians and scientists it is today.

May the coming year bring you every success and happiness!

Conflict of Interest

None declared.

\section{Reference}

1 Weber C, Lip GYH. Editor's Choice. Thromb Haemost 2019;119 (01):183-186 